[When citing this chapter, refer to Behaviour 152 (2015) 521-544]

\title{
Preference or paradigm? Bonobos show no evidence of other-regard in the standard prosocial choice task
}

\author{
Jingzhi Tan ${ }^{\mathrm{a}, *}$, Suzy Kwetuenda ${ }^{\mathrm{b}}$ and Brian Hare ${ }^{\mathrm{a}, \mathrm{c}}$ \\ ${ }^{a}$ Department of Evolutionary Anthropology, Duke University, Durham, NC, USA \\ ${ }^{\mathrm{b}}$ Lola ya Bonobo, Kinshasa, Democratic Republic of Congo \\ ${ }^{c}$ Center for Cognitive Neuroscience, Duke University, Durham, NC, USA \\ *Corresponding author's e-mail address: jingzhi.tan@duke.edu
}

Accepted 4 August 2014; published online 19 September 2014

\begin{abstract}
Bonobos are the only ape species, other than humans, that have demonstrated prosocial behaviors toward groupmates and strangers. However, bonobos have not been tested in the most frequently used test of prosociality in animals. The current study tested the other-regarding preferences of bonobos in two experiments using the prosocial choice task. In the first experiment subjects preferred a food option that would benefit both themselves and another bonobo. This preference was likely the result of a location bias developed in the pretest since they showed the same preference in the non-social control condition within test sessions. A second experiment was designed to help subjects overcome this bias that might interfere with their social choices. Bonobos again did not prefer to choose the prosocial option. However, results suggest constraints of this paradigm in revealing social preferences. In discussing our results we consider why bonobos show robust prosocial preferences in other paradigms but not here. While others have suggested that such contradictory results might suggest interesting motivational or cognitive differences between humans and non-humans, we propose that the current 'standard' paradigm has failed validation due to three methodological constraints. Across the dozens of studies completed few have demonstrated that non-human subjects understand the causal properties of the apparatus, non-social biases quickly develop in inadequately counterbalanced pretests that typically explain subjects' choices in the test, and even human children found this choice task too cognitively demanding to consistently show prosocial preferences. We suggest it is time to consider switching to a variety of more powerful and valid measures.
\end{abstract}

\section{Keywords}

bonobo, Pan paniscus, prosocial behavior, other-regarding preferences. 


\section{Introduction}

A central question in animal cognition is the origin of human sharing and cooperation. Nonhuman animals and humans have been compared for their prosocial behaviors and the underlying motivations. Currently there is tension in the literature regarding the extent to which non-human primates share prosocial preferences with humans (Cronin, 2012). Some studies suggest that non-human primates are willing to help and share without immediate, tangible rewards (i.e., they are showing other-regarding preferences, Burkart et al., 2007; Warneken et al., 2007; de Waal et al., 2008; Lakshminarayanan \& Santos, 2008; Cronin et al., 2010; Massen et al., 2010; Horner et al., 2011; Melis et al., 2011; Yamamoto et al., 2012). Other studies report negative results suggesting that non-human primates are not motivated to help or share even when there is no cost to the actor (Silk et al., 2005; Jensen et al., 2006; Vonk et al., 2008; Cronin et al., 2009; Stevens, 2010; Silk \& House, 2011; Skerry et al., 2011; Liebal et al., 2014). Resolving this disagreement will be required in order to understand the evolution of human other-regarding preferences.

Bonobos are one of our species' two closest relatives. Their close phylogenetic relationship to humans makes them especially important to understand when testing hypotheses regarding human cognitive evolution. In the case of prosocial behaviors, bonobos, like humans and chimpanzees, are prosocial toward groupmates in various forms. They spontaneously console victims of aggression (Clay \& de Waal, 2013a, b). This consolation reduces the anxiety level of the victims and protects them from future aggression (Palagi \& Norscia, 2013). In an experimental context, bonobos voluntarily disengage from playing to help groupmates obtain out-of-reach food, even when there are no immediate, tangible rewards (Tan \& Hare, 2013, 2014).

Bonobos are especially important in understanding human sharing since in this regard they are very different from chimpanzees (Hare et al., 2012). Several differences between the two Pan species make bonobos a strong candidate for human-like other-regarding preferences: First, relative to chimpanzees bonobos are highly food tolerant. Bonobos co-feed on the same food resource that quickly becomes monopolizable between chimpanzees (Hare et al., 2007; Wobber et al., 2010a; but see Jaeggi et al., 2010a), obtain equal food shares after collaboration (Hare et al., 2007), and become anxious compared to chimpanzees in anticipation of food being monopolized (Wobber et al., 2010b). Second, relative to the xenophobia observed in chimpanzees, 
bonobos are highly tolerant toward strangers (Wrangham, 1999; Tan \& Hare, 2013, 2014). In the wild intergroup encounters of bonobos can be affiliative with strangers and engage in grooming, genital rubbing, copulation and cofeeding (Furiuichi, 2011). Transferring bonobos between groups is relatively free of aggression compared to chimpanzee transfer (Idani, 1991; Pfalzer \& Ehret, 1995; Gold, 2001). Third, bonobos are prosocial toward strangers without immediate, tangible rewards. In two recent studies, bonobos voluntarily shared monopolizable food with a stranger and preferred to share with a stranger over a groupmate (Hare \& Kwetuenda, 2010; Tan \& Hare, 2013). In a helping task, bonobos are also willing to pay an energetic cost to help a stranger obtain out-of-reach food (Tan \& Hare, 2013; see also Tan \& Hare, 2014). These findings illustrate the unique character of the bonobo social system and raise the possibility that bonobos show high levels of other-regard previously thought to be unique to humans.

While bonobos have shown choices consistent with other-regard toward groupmates and strangers in multiple paradigms, they have yet to be tested using what has become the 'standard' non-verbal method for measuring prosociality. First developed by Silk et al. (2005) and Jensen et al. (2006), the standard approach to examining prosocial preferences requires subjects to make a direct choice between a prosocial option, which delivers a food reward to both the actor and a recipient in an adjacent room (1/1), and an asocial option, which delivers the same amount of food to the actor but none to the recipient $(1 / 0)$. Because the payoff to the subjects is identical in either option, subjects should show a preference for the prosocial option that benefits the recipient if they have other-regarding preferences. As shown in Table 1, variations of the prosocial choice task have been administered in six non-human primate species representing New World monkeys, Old World monkeys and great apes (and even non-primates, e.g., Di Lascio et al., 2013). Although these studies yield inconsistent results within and between species (Cronin, 2012), many have taken them as core evidence to support human uniqueness in sharing (e.g., Jaeggi et al., 2010b; Silk \& House, 2011, 2012; Jensen, 2012).

Here we tested whether bonobos, whose prosociality is well-established in other contexts, would be prosocial in what many think of as the conventional task (Jensen, 2012; Silk \& House, 2012). Bonobos should prefer to aid the recipient given their high level of social tolerance and observed other-regarding preferences in other contexts. In experiment 1 benefiting the 


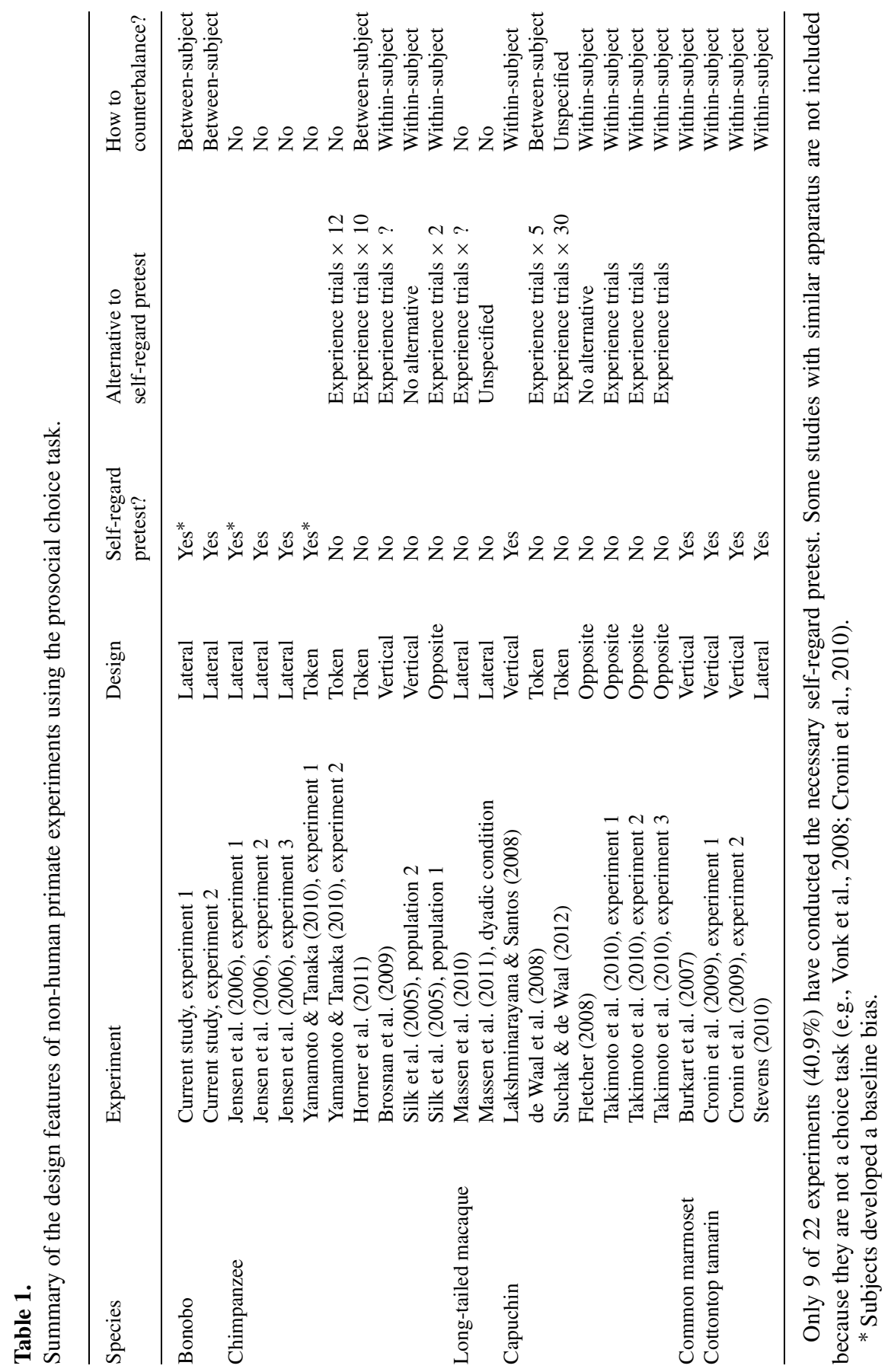


recipient (a groupmate or a stranger) was cost-free because subjects received equal rewards if they chose either a selfish or other-regarding option; in experiment 2 subjects had to pay a cost to benefit the recipient, making their prosocial preference costlier.

\section{Experiment 1}

In this experiment subjects were presented with a prosocial option and an asocial option (see Figure 1a). The prosocial option (the 1/1 option) had two slices of food with one delivered to the subject and the other to a recipient. The asocial option (the 1/0 option) also had two slices with one delivered to the subject and the other discarded by experimenters. To increase the intuitiveness of the task, we have two human experimenters each holding a plastic tray to present and distribute the options. We chose this social presentation method since this approach has been used successfully in a variety of tasks (in some cases leading to improved performance over nonsocial versions, e.g., Wobber \& Hare, 2009; Wobber et al., 2010a).

One important methodological feature here is that we included a pretest to show that our subjects could take advantage of their understanding of this paradigm to maximize their own benefits before testing whether they provided benefits to others (i.e., they showed self-regards before being tested for other-regards). To show self-regard understanding, we tested each subject alone, allowed them free access to the recipient room, and presented them with exactly the same options they would receive in the test phase (i.e., 1/1 and 1/0). They would receive one extra unit of food by choosing $1 / 1$ because they could travel to the recipient room. Only if they prefer the 1/1 option in this context will they demonstrate an understanding of the consequences to themselves and to the recipient room (Jensen et al., 2006; Melis et al., 2010; Hare \& Tan, 2011). We assume that subjects had the basic understanding that conspecifics would eat food. Once subjects knew which option would deliver food to the recipient room, they would therefore understand that the food would be consumed if another bonobo were in the room. Without such a demonstration of self-regards, one cannot determine whether subjects lose track of where the food pieces would go or perceive the task as food competition against the recipient (see Table 1 for a summary of published prosocial choice experiments). 

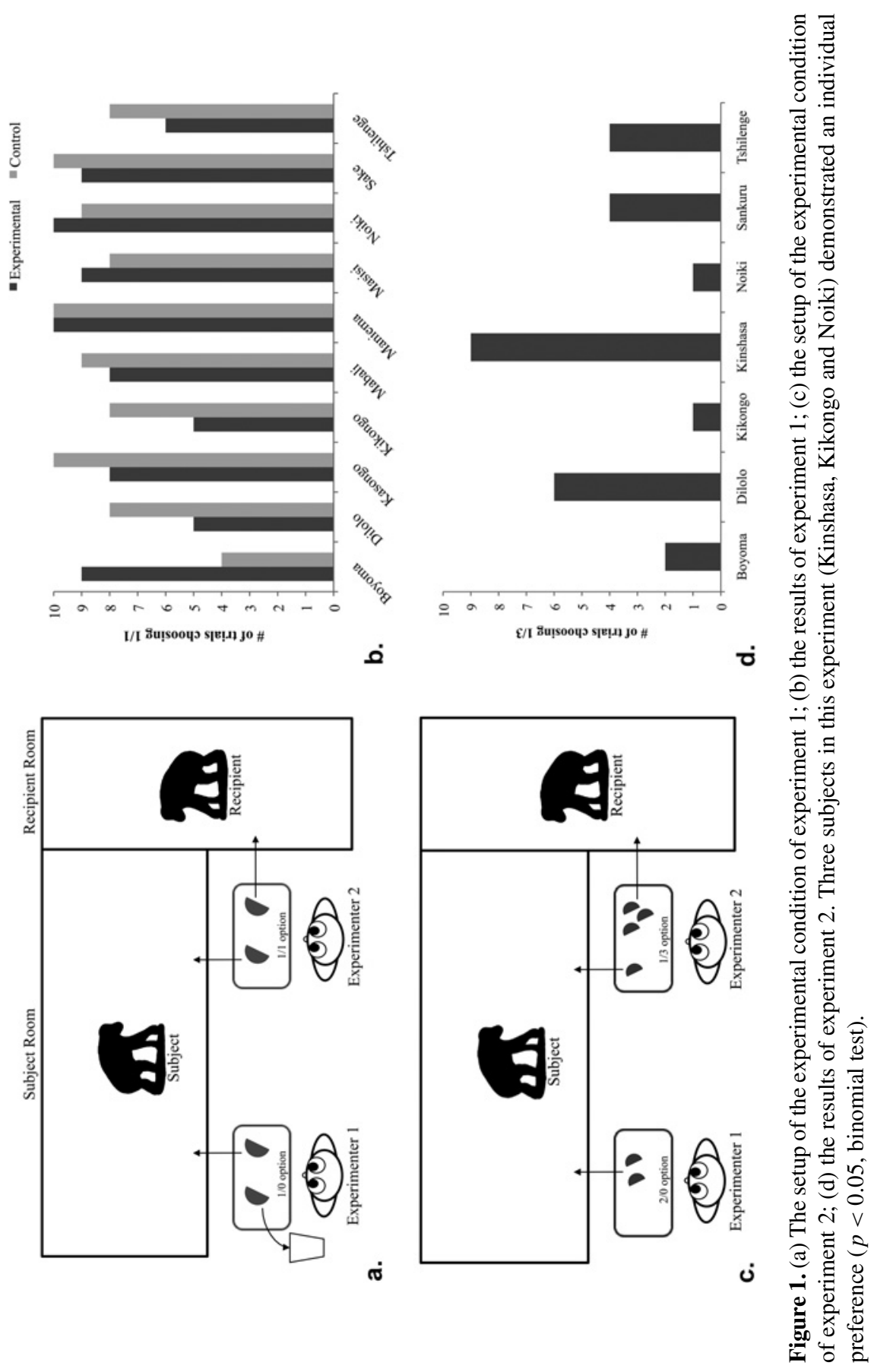


\subsection{Methods}

\subsubsection{Subjects}

Ten bonobos (4M:6F) from Lola ya Bonobo sanctuary were tested in this experiment (mean age $8.20 \pm 0.59$, Table 2). All bonobos lived in one of three social groups with access to large forested enclosures in the day and indoor sleeping enclosures at night. Although they were orphans from bushmeat trade, it is evident that the cognition of orphan bonobos was not different from that of mother-reared bonobos (Wobber \& Hare, 2011). Subjects could quit at any time by refusing to eat and/or sitting next to the exit of the testing rooms. Ten other bonobos participated but did not finish the pretest phases because three were uncomfortable being separated (Fizi, Lisala and Opala) and seven could not pass the pretests by the end of our field trip (Api, Kalina, Katako, Luozi, Sankuru, Tembo and Waka). Subjects were never food-/water-deprived. To maximize subjects' motivation, the experiment was conducted prior to their morning or afternoon meal.

Each subject was paired with a recipient in the experimental trials of the test phase (see Procedure). Nine bonobos (5M:4F) played the role of the recipient and three of them were also subjects (Boyoma, Kikongo, and Noiki). In five pairs, the recipient was a familiar groupmate; in the other five pairs, the recipient was a stranger from another social group. We maximized possible combinations by including as many individuals as possible to play

\section{Table 2.}

Participant information of experiment 1.

\begin{tabular}{|c|c|c|c|c|c|c|c|}
\hline \multicolumn{3}{|c|}{ Subject } & \multicolumn{5}{|c|}{ Recipient } \\
\hline Name & Sex & Age* & Name & Sex & Age* $^{*}$ & Familiarity & Location \\
\hline Boyoma & M & 6 & Noiki & $\mathrm{F}$ & 11 & Ingroup & Left \\
\hline Dilolo & M & 10 & Lukuru & $\mathrm{F}$ & 6 & Outgroup & Left \\
\hline Kasongo & M & 9 & Chibombo & M & 6 & Outgroup & Right \\
\hline Kikongo & M & 9 & Api & M & 9 & Ingroup & Right \\
\hline Mabali & M & 10 & Kodoro & M & 4 & Outgroup & Right \\
\hline Maniema & M & 8 & Kikongo & M & 9 & Ingroup & Left \\
\hline Masisi & $\mathrm{F}$ & 6 & Chibombo & M & 6 & Outgroup & Left \\
\hline Noiki & F & 11 & Boyoma & M & 6 & Ingroup & Right \\
\hline Sake & F & 6 & Katako & $\mathrm{F}$ & 7 & Outgroup & Right \\
\hline Tshilenge & F & 7 & Muanda & $\mathrm{F}$ & 6 & Ingroup & Left \\
\hline
\end{tabular}

\footnotetext{
* Based on estimates from Wobber et al. (2010b).
} 
the role of recipient. To exclude potential reciprocity during the experiment, the subjects and the recipients did not reverse their roles except in the pairs of Noiki and Boyoma (this was due to the availability of other participants, e.g., they were sick or in the forest). In total, we created 10 dyads comprised of 16 unique individuals.

\subsubsection{Setup}

The general setup consisted of two adjacent testing rooms, the subject room and the recipient room (Figure 1a). The experiment was conducted in two different buildings. In one building, both rooms were $15 \mathrm{~m}^{2}$; in the other building, the recipient room was $8.6 \mathrm{~m}^{2}$, and the subject room was $15 \mathrm{~m}^{2}$. The two rooms were separated by mesh and were connected by a sliding door. Two experimenters each held a blue, plastic tray $(30 \times 20 \mathrm{~cm})$ in front of the subject room to present food. The trays were two meters apart and were controlled by coordinated behaviors of the experimenters so that subjects could never reach both simultaneously (see Procedure). Therefore, subjects could only choose one tray. Fruit slices (bananas or apples) were used as reward.

\subsubsection{Procedure}

The experiment consisted of four phases: number pretest, experience pretest, self-regard pretest and test. Each phase followed the general procedure with two experimenters (E1, E2) holding and controlling the food trays as well as a third experimenter (E3) centering the subject. A trial began as E3 lured the subject to the middle point between E1 and E2 with milk or peanuts. E1 and E2 simultaneously showed the contents of the food trays by holding them in front of the subject and calling its name three times. They then quickly pushed the trays aside to two predetermined locations that were $2 \mathrm{~m}$ apart and against the mesh. The subject had $60 \mathrm{~s}$ to make a choice. The holder of the chosen tray distributed the food according to the rules of specific phases; meanwhile the other experimenter immediately retracted the other tray. A trial was aborted and re-run immediately if the subject did not make a choice within $60 \mathrm{~s}$ or if it moved to either side before the trays were pushed forward. Each phase was usually finished in one testing day. If subjects lost motivation, they continued on a subsequent day.

2.1.3.1. Number pretest. This phase was designed to test whether the subjects could discriminate quantities and choose between the contents of the food trays. The subjects were individually tested in the subject room. In each 
trial, one tray contained one slice of food while the other had two slices. The quantities of food on the two trays were switched every trial, and the locations of E1 and E2 were switched every other trial. The subject was directly handed all the food on the chosen tray. The subject could proceed to the next phase if they made correct choices in 8 out of 10 consecutive trials within one day. For those who succeeded in passing the criterion, the average number of trials needed was $18.10 \pm 7.20$ (10-28 trials).

2.1.3.2. Experience pretest. This was a four-trial session designed to introduce the $1 / 0$ option to the subjects. This phase was similar to the number pretest with three major exceptions. First, an opaque bucket would be placed next to the experimenter who was at the distal side of the recipient room. The bucket was out of the subject's reach and was shown to the subject that it was empty at the beginning of this pretest. Therefore, one tray was proximal to the recipient room (a.k.a. the recipient tray) and the other was proximal to the bucket (a.k.a. the bucket tray). Second, the bucket tray represented the $1 / 0$ option. It always contained two slices of food but only delivered one slice to the subject if chosen. The holder picked up the first slice, showed it to the subject, called its name twice to attract attention, dropped that slice into the bucket, and then gave the second slice to the subject. The recipient tray was always empty to make sure that the subject would pay attention to the bucket tray. Third, the locations of the two trays (and the two rooms) did not change within subjects but were counterbalanced between subjects. E1 and E2 switched locations every trial. One subject (Dilolo) did not participate in this pretest because we directly administered the trials of the next phase by mistake, but he did experience the 1/0 option at least four times during the next phase (see below).

2.1.3.3. Self-regard pretest. This phase was designed to demonstrate that the subject understood the consequences of each option. In this pretest, the door connecting the subject room and the recipient room was open, allowing the subject to freely travel between both rooms. Like the experience pretest, the bucket tray contained two slices of food and only one slice would be given to the subject (1/0). Here the recipient tray also contained two fruit slices and represented the $1 / 1$ option. If chosen, the experimenter showed the first slice to the subject, called its name twice to attract attention, dropped that slice in the recipient room, and directly handed the second slice to the subject. Therefore, the recipient tray gave the subject both slices, one in 
the subject room and the other in the recipient room. The locations of the two trays were consistent with the experience pretest and counterbalanced between subjects. E1 and E2 switched locations every trial. The subject could proceed to the next phase if they chose the recipient tray in 8 of 10 consecutive trials. The average number of trials needed was $12.40 \pm 5.95$ (8-25 trials).

2.1.3.4. Test. This 20-trial session consisted of two types of trials. The first and the last five trials were control trials, while the 10 trials in the middle were experimental trials. The contents and locations of the food trays were similar to the self-regard pretest, but the door connecting the subject room and the recipient room was closed. In the experimental trials, a recipient was in the recipient room (see Figure 1a); in the control trials, the recipient room was empty. Because the subject could not enter the recipient room, it received only one slice no matter which tray it chose. However, in the experimental trials choosing the recipient tray would donate one slice to the recipient (i.e., the prosocial option) while choosing the bucket tray would leave the recipient with nothing (i.e., the asocial option).

\subsubsection{Coding and analysis}

A choice was coded if the subject stuck out fingers, lips or straws toward one tray through the mesh, or if they sat down in front of one tray with their body touching the mesh. We did not code gestures of the recipient due to the narrow mesh of some testing rooms that blocked gestural attempts. A second coder coded all the trials and inter-coder reliability was perfect (Cohen's kappa $=1$ ). All statistics were two-tailed and non-parametric due to limited sample size.

\subsection{Results}

Figure $1 \mathrm{~b}$ demonstrates the main results of experiment 1 . The subjects preferred the $1 / 1$ option to the $1 / 0$ option in both the experimental and the control conditions (experimental: mean $=7.90 \pm 1.77, N=10, p=0.011$; control: mean $=8.40 \pm 1.76, N=10, p=0.006$, one-sample Wilcoxon signed rank test, two-tailed). However, their preferences for the $1 / 1$ option did not differ between the two conditions throughout the test phase $(N=10$, $Z=1.018, p=0.309$, one tie, Wilcoxon signed rank test, two-tailed). Neither stranger pairs nor groupmate pairs showed a preference (stranger: $N=5, Z=-1.511, p=0.131$, no tie; groupmate: $N=5, Z=0, p=1.0$, 
one tie; all Wilcoxon signed rank test, two-tailed). In either condition, the subjects' preferences did not differ when the first 5 and the last 5 trials were compared (experimental: $N=10, Z=0.333, p=0.739$, four ties; control: $N=10, Z=0.966, p=0.334$, five ties, Wilcoxon test, two-tailed). At the individual level, in each condition there were five subjects choosing the 1/1 option for 9 or 10 times (see Figure 1b). We scored the difference in the frequency of choosing the 1/1 option between the experimental and the control condition as an index of each subject's prosociality. The recipient's group membership had no effect on this difference score $(N=10, U=9.5$, $p=0.526$; Mann-Whitney $U$-test, two-tailed).

\subsection{Discussion}

Although the subjects preferred the prosocial option to the asocial option when the recipient was present, they showed the same preference when the recipient was absent. If we consider only the pairs of strangers or only those of groupmates, the results remain the same. The individual analysis is consistent with this pattern. Half of the subjects preferred the 1/1 option in the control condition. This result suggests that subjects have developed a bias toward the content or the location of the 1/1 option.

It is unlikely that the subjects were simply attracted by the content of the $1 / 1$ option because both options always contained two pieces of food. Alternatively, the subjects might have preferred the 1/1 option in an attempt to retrieve the fruit slice delivered into the recipient room even though they had no access. However, they were tested in their sleeping building and thus understood the separation caused by the sliding door.

The subject's apparent location bias was likely introduced during the selfregard pretest because the subjects were required to choose the 1/1 option 8 of 10 times before the test phase. In the test phase the two options conferred equal payoff to the subjects, so there was no cost to them if they kept choosing the same location. Our results are consistent with two chimpanzee experiments with a similar self-regard pretest (Jensen et al., 2006, experiment 1; Yamamoto \& Tanaka, 2010, experiment 1). Experiment 1 of Jensen et al. (2006) had a similar lateral setup of the two options, and their subjects developed a location bias toward the 1/1 option; in experiment 1 of Yamamoto \& Tanaka (2010), their subjects were trained to associate each option with a button in a fixed color and developed a location bias toward one particular color. 
Some proposed to avoid this problem by not conducting the self-regard pretest (Horner et al., 2011). We disagree with this proposal because it will be unclear whether subjects understand the consequences of their choices. Placing this self-regard phase after the test phase is also problematic since it is possible that subjects enter the test phase without any understanding of the setup but gradually develop such understanding during the test. Others suggested that this location bias could be avoided by making the location of the prosocial option contrary to the biased location so that subjects would clearly have overcome the pre-existing bias if they show a prosocial preference (Massen et al., 2010). Similarly in a token-exchange version of this task, Horner et al. (2011) designated the least preferred token in the baseline as the prosocial token in the test phase.

Following this logic we kept the self-regard pretest and adjusted the reward distributions in the second experiment. The prosocial option delivered one fruit slice to the subjects and three slices to the recipient room (1/3). The other option consisted of two pieces and all went to the subjects (2/0). In the self-regard pretest subjects would have to prefer the $2 / 0$ option to understand they would obtain less food if the $1 / 3$ option were chosen because the access door between rooms was closed; in the test they would need to choose the $1 / 3$ option to benefit the recipient (and thus overcome the location bias toward the $2 / 0$ option). As a result, we also created a costly sharing situation where the prosocial act could be regarded as altruistic.

\section{Experiment 2}

This experiment presented subjects with an asocial option and a prosocial option (Figure 1c). The asocial option (the $2 / 0$ option) had two slices of food that would all be given to the subjects; while the prosocial option (the 1/3 option) had four slices with one delivered to the subjects and three to the recipient.

\subsection{Methods}

\subsubsection{Subjects}

Seven bonobos (3M:4F) participated in this experiment. Five of them were subjects in experiment 1 (Table 3). Four other bonobos were dropped out of the experiment because they were not able to pass the pretests by the end of our field trip (Mabali, Maniema, Muanda and Tembo). Each subject 
Table 3.

Participant information of experiment 2.

\begin{tabular}{lcrlllll}
\hline & Subject & & & \multicolumn{4}{c}{ Recipient } \\
\cline { 5 - 6 } Name & Sex & Age* & & Name & Sex & Age* & Location \\
\hline Boyoma & M & 6 & & Noiki & F & 11 & Right \\
Dilolo & M & 10 & & Mabali & M & 10 & Right \\
Kikongo & M & 9 & & Tchilenge & F & 7 & Left \\
Kinshasa & F & 6 & & Muanda & F & 6 & Left \\
Noiki & F & 11 & & Kikongo & M & 9 & Left \\
Sankuru & F & 11 & & Tchilenge & F & 7 & Right \\
Tshilenge & F & 7 & & Kikongo & M & 9 & Left \\
\hline
\end{tabular}

* Based on estimates from Wobber et al. (2010b).

was paired with a groupmate recipient since in experiment 1 there was no difference in prosociality between stranger pairs and groupmate pairs. Five bonobos played the role of recipient and three of them were also subjects (Kikongo, Noiki and Tchilenge). We followed the same rules as in experiment 1 to determine the pairings. There was no role-reversal except in the pairs of Kikongo and Tchilenge due to the availability of other participants. In total, we created seven dyads comprised of nine unique individuals.

\subsubsection{Setup and procedure}

Figure 1c shows the setup of the current experiment. Its setup and general procedure were identical to experiment 1 with two food trays and three experimenters. This experiment consisted of four phases: number pretest I, number pretest II, self-regard pretest and test. Each phase was usually finished in one testing day.

3.1.2.1. Number pretest I. This phase was designed to test whether subjects could distinguish different contents on the food trays. It was identical to the number pretest in experiment 1 (i.e., one piece versus two pieces). The subject could proceed to the next phase if they chose the option with two food slices in 8 of 10 consecutive trials. The average number of trials needed was $16.14 \pm 6.41$ (10-26 trials).

3.1.2.2. Number pretest II. This phase was designed to test whether the subjects could prefer four fruit slices to two. It was identical to the number pretest I except that one tray contained two slices and the other contained four. Subjects needed $10.14 \pm 1.25$ (9-13) trials to pass this phase. 
3.1.2.3. Self-regard pretest. This phase was designed to introduce the $1 / 3$ and the $2 / 0$ options and demonstrate that the subjects understood the consequences of each option. In this phase, the recipient room was empty and was separated from the subject room by open mesh. The recipient tray was the $1 / 3$ option and always contained four fruit slices. If the subjects chose this tray, the holder picked up three slices, showed them to the subject by calling its name twice, dropped them into the recipient room and directly handed the remaining slice to the subject at the end. The subject could see but could never retrieve the food in the recipient room (i.e., a 1/3 payoff). The other tray contained two slices. The subject would receive all of them if it chose it (i.e., a 2/0 payoff). The location of the recipient room (and the recipient tray) did not change within subjects but was counterbalanced between subjects. The two tray-holders switched locations every trial. To pass this phase, the subject had to choose the $2 / 0$ option in 8 of 10 consecutive trials. The average number of trials needed was $28.43 \pm 10.72$ (16-46 trials). Because we needed to establish a preference for the $2 / 0$ option here, we could not open the door to the recipient room as we did in experiment 1 . However, since subjects have already demonstrated that they paid attention to the tray with four pieces in the number pretest II, their preference for $2 / 0$ to $1 / 3$ in the current phase suggests that they have now understood the payoffs of each option to self and to the recipient room.

3.1.2.4. Test. This session has 10 trials and was identical to the self-regard pretest except that there was a recipient in the recipient room. The test was conducted no more than one day after the self-regard pretest. The locations of the two options were the same as the self-regard pretest. Therefore, choosing the $1 / 3$ option was altruistic because it benefited the recipient at a cost to the subject. Moreover, an altruistic choice would require the actor to overcome any location bias toward the $2 / 0$ option established in the self-regard pretest. It is important to note that here we compared subjects' choices to chance level, instead of comparing a social condition to a non-social condition. This was because if we had administered a non-social condition, it would be equivalent to the self-regard pretest and subjects would have more experience in this hypothetical non-social condition than in the social condition.

\subsubsection{Coding and analysis}

All coding followed the same criteria as in experiment 1. A second coder coded all trials and inter-coder was perfect (Cohen's kappa $=1$ ). Due to limited sample size, all statistics were non-parametric and two-tailed. 


\subsection{Results}

As shown in Figure 1d, subjects as a group did not prefer any option (mean $=$ $3.86 \pm 2.91, N=7, p=0.303$, one-sample Wilcoxon signed rank test, twotailed). They did so in the first and the second half of the test (first half: mean $=2.14 \pm 1.46, N=7, p=0.391$; second half: mean $=1.71 \pm 1.49$, $N=7, p=0.2$, one-sample Wilcoxon signed rank test, two-tailed). At the individual level, three subjects showed a preference of one option in 9 of 10 trials: Noiki and Kikongo preferred the 2/0 option, and Kinshasa preferred the $1 / 3$ option.

\subsection{Discussion}

The bonobos did not prefer the $2 / 0$ option collectively, although two subjects did show such an individual preference. They did not prefer the $1 / 3$ option as a group either, but one individual preferred the $1 / 3$ option. It is plausible that the subjects at least demonstrated some degree of prosociality because they did not overwhelmingly choose the 2/0 option (Massen et al., 2010). A more parsimonious interpretation is that subjects' choices might have been affected by local enhancement, i.e., they were attracted by the presence/proximity of the recipient so that they did not exclusively choose the $2 / 0$ option during the test (Jaeggi et al., 2010b). Finally similar to Jensen et al. (2006) the current results show considerable individual variability with two subjects sticking to the selfish option and one subject preferring the altruistic option. Future research should adjust the payoffs of the two options to examine if subjects are sensitive to the cost of the prosocial option. For example, when the selfish option becomes $4 / 0$, if subjects choose $4 / 0$ less often when the prosocial option is $3 / 1$ than when it is $1 / 3$, it would suggest that subjects' choices were not simply a result of local enhancement.

\section{General discussion}

Overall we found little evidence for other-regarding preferences in this prosocial choice task with bonobos. In experiment 1 the subjects could aid a stranger or a groupmate recipient at no cost to themselves, but they showed a preference for the prosocial option regardless of the presence of the recipient. Because both options in experiment 1 had the same amount of food, the observed preference was likely due to a bias toward the location of the prosocial option developed during the self-regard pretest. In experiment 2 prosocial choices could not be explained by a location bias since subjects 
had to choose the opposite location chosen in the pretest. In addition, they would obtain less food by doing so. As a group the bonobos showed no preference for any option or location with two subjects preferring the selfish option and one preferring the altruistic option, which could be explained parsimoniously by local enhancement.

One interpretation of our results is that bonobos, like chimpanzees, show little evidence of other-regard in this paradigm, which supports the argument that humans have unique propensity to share among great apes (Warneken \& Tomasello, 2009; Jaeggi et al., 2010b; Silk \& House, 2011, 2012; Jensen, 2012). The genus Pan may have psychological constraints preventing the expression of other-regard in the prosocial choice task and, by extrapolation, the context of food provisioning more generally (Warneken \& Tomasello, 2009; Silk \& House, 2011). Although the current study could not rule out this food inhibition hypothesis, it has been repeatedly challenged by findings that bonobos and chimpanzees demonstrate other-regard in other tasks that directly provision the recipient with food (Greenberg et al., 2010; Melis et al., 2011; Tan \& Hare, 2013). In fact, chimpanzees, which are highly competitive over food, show other-regard in some other tasks using visible food, invisible food and non-food (Warneken et al., 2007; Melis et al., 2011), whereas reducing the visibility of food does not necessarily lead to positive results in the prosocial choice task (Vonk et al., 2008). If the relatively foodintolerant chimpanzees appear unaffected by the presence or the visibility of food, these factors should not constrain the prosociality of the relatively food-tolerant bonobos (see also Cronin, 2012).

Alternatively our results may tell us more about methodological constraints intrinsic to this standard paradigm for prosociality. Given this task requires the use of an apparatus, subjects must first show they understand the physical setup by demonstrating self-regard (Jensen et al., 2006; Melis et al., 2010; Hare \& Tan, 2011). However, this introduction seems to create a location bias that then carries over into the test and likely interferes with any preference the subjects might naturally express. A location bias could explain all three 1/1-vs-1/0 experiments on great apes in which a selfregard pretest was conducted (Jensen et al., 2006, experiment 1; Yamamoto \& Tanaka, 2010, experiment 1; current study, experiment 1). In fact, while Jensen et al., 2006 is normally cited as evidence against other-regards in chimpanzees, the subjects in experiment 1 show a strong bias for the prosocial option in the test trial just as the bonobos do here. However, like our bonobos, the chimpanzees showed the same preference in the self-regard 
pretests and controls. This pattern does not suggest an interpretable failure on the part of the subjects.

One approach to avoid the development of a location bias is to make the prosocial choice in test trials at the opposite location from where the same food distribution was presented in the self-regard pretest. In this way subjects have to overcome the location bias to demonstrate prosocial preferences (e.g., Massen et al., 2010; Horner et al., 2011). While we have designed experiment 2 in this way, this design feature only protects against a false positive due to a location bias — but remains open to alternate interpretations such as local enhancement. Subjects could choose the prosocial option because they were simply attracted by the presence of the recipient.

Other approaches to avoid a location bias focus on removing or replacing the self-regard pretest. For example, some propose to omit the self-regard pretest or conduct it after the test phase (e.g., Horner et al., 2011; Yamamoto \& Tanaka, 2010, experiment 2). However, without a self-regard pretest it is almost impossible to know if the subjects understood the consequences of their choices in the actual test. That means any results from no-pretest experiments will be equally difficult to interpret since they might be false negative (e.g., subjects pay no attention to the other end of the apparatus) or false positive (e.g., subjects attempt to compete for the extra food piece). Table 1 shows that over $50 \%$ of published experiments omitted the selfregard pretest.

A common alternative to the self-regard pretest is experience trials (i.e., subjects are given 2-30 forced-choice trials with each option). This approach is problematic for two reasons. First, the number of experience trials given is arbitrary. No study has ever validated that amount of experience leads to an understanding of the consequences of each option. For example, the current study shows that there was tremendous variability of how much experience each subject needed to understand the consequences of each option (the number of trials needed to pass the self-regard pretest: experiment 1: 8-25; experiment 2: 16-46). Second, experience trials alone cannot show subjects understand what would happen to the recipient room. Because subjects cannot enter the recipient room, they only experience the reward of each option for themselves. This approach seems to be based on an assumption: within an arbitrary number of experience trials, their subjects will somehow pay attention and understand what happens on the other end of the apparatus through observation alone. This assumption is likely unwarranted unless an additional pretest is conducted to show that subjects indeed pay attention to 
the reward that would eventually go into the recipient room (e.g., as in the number pretest II in experiment 2 of the current paper).

The last approach is proposed by Cronin et al. (2010) to measure the change of subjects' choices over time in the test phase. For example, if their choices of the prosocial option decrease in the non-social control but not in the experimental condition, that should be evidence of prosocial preferences. However, given the Cronin study itself included a rigorous self-regard pretest, it remains to be further tested if measuring the temporal change of subjects' choices alone is sufficient. A combination of this approach and the self-regard pretest might provide the strongest evidence of subjects' understanding of the setup (as in Cronin et al., 2010).

We suggest a self-regard pretest is crucial for interpreting the results from this paradigm but that counterbalancing the location of the prosocial option is critical. As shown in Table 1, when considering experiments with a selfregard pretest, a location bias only develops in those studies using a betweensubjects design in regards to the location of the prosocial choice (or no counterbalancing at all, Jensen et al., 2006; Yamamoto \& Tanaka, 2010; the current study). This design leads to a location bias since the $1 / 1$ option, in both the pretest and the test, always leads to maximal payoff and it stays in the same location. To corroborate, studies that are able to use a design that counterbalances the location of the 1/1 option within each subject did not generate a location bias (Burkart et al., 2007; Lakshminarayana \& Santos, 2008; Cronin et al., 2009; Stevens, 2010). Therefore, it is not that all pretests create a location bias as previously suggested (Horner et al., 2011), but that, in particular, a between-subjects design does.

Not all designs are equal in terms of their ability to allow for a counterbalanced pretest. Table 4 presents a qualitative comparison of the four major setups previously used based on the difficulty of running self-regard pretest and that of counterbalancing the choice options within subjects. For example, when subjects face each other across opposite rooms no experiments have conducted a self-regard pretest (Silk et al., 2005; Fletcher, 2008, population 1; Takimoto et al., 2010). This is likely because the necessary configuration of rooms that would allow for a subject to travel in a separate tunnel to the recipient room for the pretest typically does not exist. In addition, while the 'opposite' and 'vertical' designs allow for easy counterbalancing, the 'lateral' and 'token' designs do not and likely encourage competing biases to develop in the pretest. One notable exception is the lateral design used by Stevens (2010), in which within-subject counterbalancing occurred 
Bonobos are indifferent in 'the' prosociality task

$539[293]$

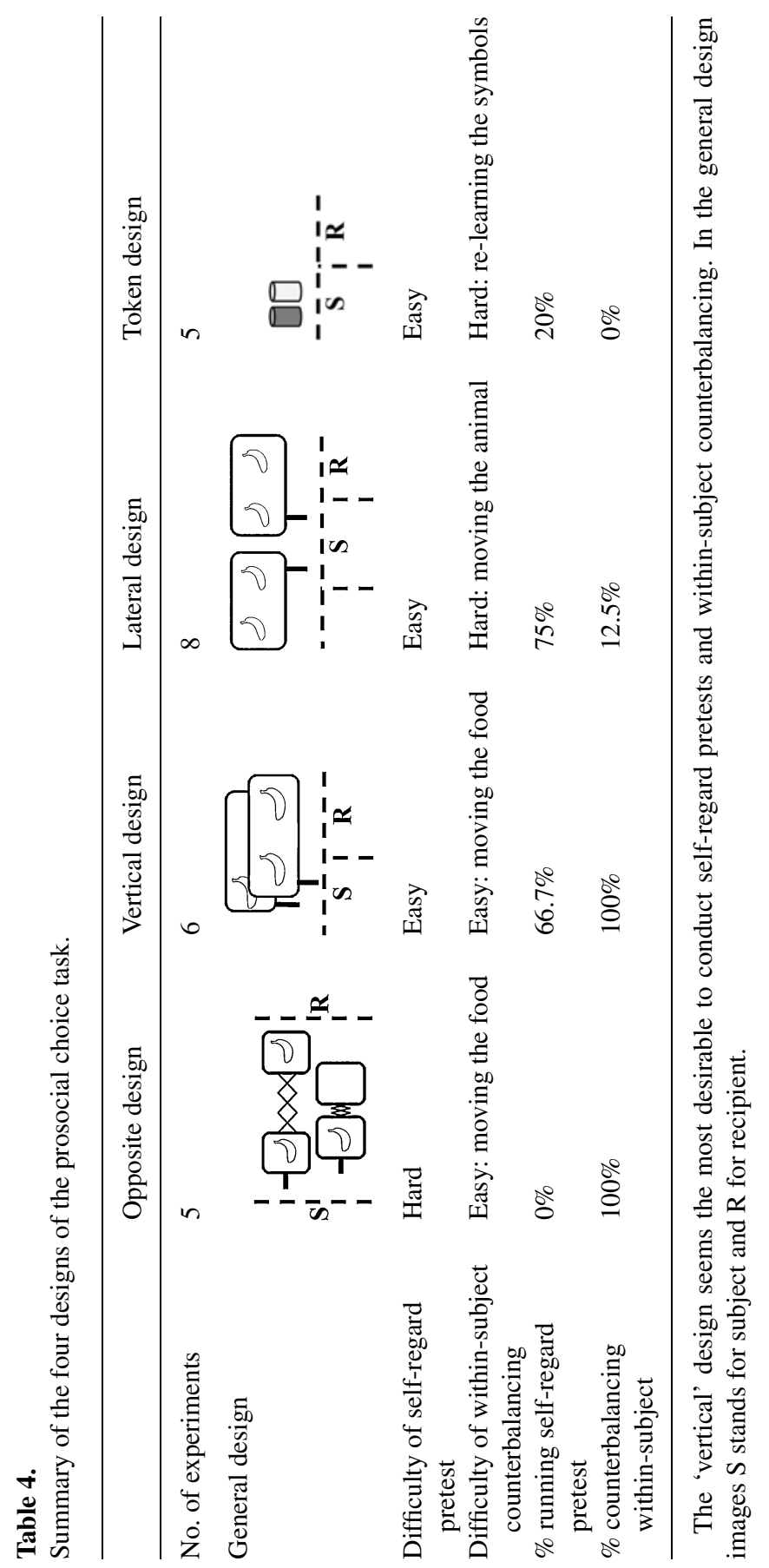


between test sessions given the small size of the species being tested (i.e., the experiment did not have to be designed around the constraints of the available housing as in ape studies). Overall the vertical design seems to be the most desirable: it accommodates the needs of a self-regard pretest and within-subject counterbalancing, plus it controls for local enhancement.

A lack of self-regard pretest and inadequate counterbalancing are only part of the challenges to the overall validity of the standard prosocial choice task. For example, Burkart \& Rueth (2013) found that even 2-5-year-old human children failed to show prosocial preference when choosing between $1 / 1$ and $1 / 0$, but the same subjects were prosocial when choosing between $0 / 1$ and $0 / 0$. It is important to note that their subjects all received self-regard pretest and within-subject counterbalancing in a vertical design task (see House et al., 2012 for a similar result in children with an opposite design). As suggested by the authors, making a choice between $1 / 1$ and 1/0 seems too taxing for the subjects because they had to encode and consider payoffs of four food dishes at once. That means any prosocial choice task using $1 / 1$ and $1 / 0$ might create false negative regarding prosocial preferences as it did in human children. Interestingly, an effective approach to reduce the cognitive load is to use $0 / 1$ and $0 / 0$ as payoff options (Burkart \& Rueth, 2013). This essentially turns the standard prosocial choice task into an instrumental helping task (see also Cronin et al., 2010).

The question of ape prosocial and other regarding preferences is central to understanding the evolution of human sharing and cooperation. However, while a variety of tasks have consistently revealed helping and sharing in both bonobos and chimpanzees (Warneken et al., 2007; Hare \& Kwetuenda, 2010; Melis et al., 2011; Yamamoto et al., 2012; Tan \& Hare, 2013, 2014), studies using the standard prosocial choice task with apes have largely produced negative results (Silk et al., 2005; Jensen et al., 2006; Brosnan et al., 2009; Yamamoto \& Tanaka, 2010; current study). In interpreting this literature some have weighted the negative findings in the prosocial choice task heavier than the positive results in other experimental tasks (Silk \& House, 2011; Jensen, 2012). However, while positive results using other paradigms have included pretests in which subjects successfully demonstrated an understanding of the apparatus (e.g., Warneken et al., 2007; Tan \& Hare, 2013) most prosocial choice tasks have either failed to show subjects understand the task or omitted the pretest all together (see Table 1). In addition, while quantitative comparisons between chimpanzees and human infants have shown 
highly similar results in instrumental helping tasks (Warneken et al., 2007), even human children show inconsistent results in standard prosocial choice tasks (Brownell et al., 2009; House et al., 2012; Burkart \& Rueth, 2013). Our results and literature review suggest at least three constraints intrinsic to the standard prosocial choice paradigm: a lack of self-regard pretest, inadequate counterbalancing and unnecessary cognitive load. Taken together, it is difficult to conclude that standard prosocial choice tasks provide a valid measure of prosociality or other-regard. While a species failure to solve a problem or show a preference can often be interpreted as a meaningful difference between human and non-human apes (e.g., Hare \& Tomasello, 2004; Melis et al., 2009; Wobber et al., 2014) that is currently not the case for the standard prosocial choice task. The failure of bonobos, chimpanzees and children in this task and the strength of evidence from other paradigms raise serious questions about the validity of this approach as a vehicle to powerfully compare human and non-human prosociality. Future prosocial choice studies using a vertical task design with $0 / 1$ and $0 / 0$ payoff options may allow researchers to circumvent the method constraints we outline, but essentially this would only replicate the decision subjects face in previously published instrumental tasks where there are already clear positive results across a range of species.

\section{Acknowledgements}

This work was supported by the European Research Council (No. 233297) and National Science Foundation (BCS-27552; BCS-25172) to B.H. We are grateful to Claudine André, Dominique Morel, Dhanani Valery, Fanny Mehl, Delphin Bilua and the staff of Lola ya Bonobo for their support. We thank Melissa Klein for assistance in coding. We are very thankful to two anonymous reviewers for their extensive and instructive comments that have largely improved the manuscript.

\section{References}

Brosnan, S.F., Silk, J.B., Henrich, J., Mareno, M.C., Lambeth, S.P. \& Schapiro, S.J. (2009). Chimpanzees (Pan troglodytes) do not develop contingent reciprocity in an experimental task. - Anim. Cogn. 12: 587-597.

Brownell, C., Svetlova, M. \& Nichols, S. (2009). To share or not to share: when do toddlers respond to another's needs? - Infancy 14: 117-130. 
Burkart, J.M. \& Rueth, K. (2013). Preschool children fail primate prosocial game because of attentional task demands. - PLoS One 8: e68440.

Burkart, J.M., Fehr, E., Efferson, C. \& van Schaik, C.P. (2007). Other-regarding preferences in a non-human primate: common marmosets provision food altruistically. — Proc. Natl. Acad. Sci. USA 104: 19762-19766.

Clay, Z. \& de Waal, F.B.M. (2013a). Bonobos respond to distress in others: consolation across the age spectrum. - PLoS One 8: e55206.

Clay, Z. \& de Waal, F.B.M. (2013b). Development of socio-emotional competence in bonobos. - Proc. Natl. Acad. Sci. USA 110: 18121-18126.

Cronin, K. (2012). Prosocial behaviour in animals: the influence of social relationships, communication and rewards. - Anim. Behav. 84: 1085-1093.

Cronin, K., Schroeder, K.K.E., Rothwell, E.S., Silk, J.B. \& Snowdon, C.T. (2009). Cooperatively breeding cottontop tamarins (Saguinus oedipus) do not donate rewards to their long-term mates. - J. Comp. Psychol. 123: 231-241.

Cronin, K., Schroeder, K.K.E. \& Snowdon, C.T. (2010). Prosocial behaviour emerges independent of reciprocity in cottontop tamarins. - Proc. Roy. Soc. Lond. B: Biol. Sci. 277: 3845-3851.

de Waal, F.B.M., Leimgruber, K. \& Greenberg, A.R. (2008). Giving is self-rewarding for monkeys. — Proc. Natl. Acad. Sci. USA 105: 13685-13689.

Di Lascio, F., Nyffeler, F., Bshary, R. \& Bugnyar, T. (2013). Ravens (Corvus corax) are indifferent to the gains of conspecific recipients or human partners in experimental tasks. - Anim. Cogn. 16: 35-43.

Fletcher, G.E. (2008). Attending to the outcome of others: disadvantageous inequity aversion in male capuchin monkeys (Cebus apella). — Am. J. Primatol. 70: 901-905.

Furuichi, T. (2011). Female contributions to the peaceful nature of bonobo society. — Evol. Anthropol. 20: 131-142.

Gold, K. (2001). Group formation in captive bonobos: sex as a bonding strategy. - In: Proceedings of The Apes: Challenges for the 21st Century, Brookfield Zoo, Brookfield, IL. Chicago Zoological Society, Chicago, IL, p. 90-93.

Greenberg, J.R., Hamann, K., Warneken, F. \& Tomasello, M. (2010). Chimpanzee helping in collaborative and noncollaborative contexts. - Anim. Behav. 80: 873-880.

Hare, B. \& Kwetuenda, S. (2010). Bonobos voluntarily share their own food with others. Curr. Biol. 20: R230-R231.

Hare, B. \& Tan, J. (2011). How much of our cooperative behavior is human? - In: The primate mind: built to connect with other minds (de Waal, F.B.M. \& Ferrari, P.F., eds). Harvard University Press, Cambridge, MA, p. 175-193.

Hare, B. \& Tomasello, M. (2004). Chimpanzees are more skillful in competitive than in cooperative cognitive tasks. - Anim. Behav. 68: 571-581.

Hare, B., Melis, A.P., Woods, V., Hastings, S. \& Wrangham, R.W. (2007). Tolerance allows bonobos to outperform chimpanzees on a cooperative task. - Curr. Biol. 17: 619-623.

Hare, B., Wobber, V. \& Wrangham, R.W. (2012). The self-domestication hypothesis: evolution of bonobo psychology is due to selection against aggression. - Anim. Behav. 83: 573-585. 
Horner, V., Carter, J.D., Suchak, M. \& de Waal, F.B.M. (2011). Spontaneous prosocial choice by chimpanzees. — Proc. Natl. Acad. Sci. USA 108: 13847-13851.

House, B., Henrich, J., Brosnan, S.F. \& Silk, J.B. (2012). The ontogeny of human prosociality: behavioral experiments with children aged 3 to 8. — Evol. Hum. Behav. 33: 291-308.

Idani, G. (1991). Social relationships between immigrant and resident bonobo (Pan paniscus) females at Wamba. — Folia Primatol. 57: 83-95.

Jaeggi, A.V., Stevens, J.M.G. \& van Schaik, C.P. (2010a). Tolerant food sharing and reciprocity is precluded by despotism among bonobos but not chimpanzees. - Am. J. Primatol. 143: 41-51.

Jaeggi, A.V., Burkart, J.M. \& van Schaik, C.P. (2010b). On the psychology of cooperation in humans and other primates: combining the natural history and experimental evidence of prosociality. - Phil. Trans. Roy. Soc. B 365: 2723-2735.

Jensen, K. (2012). Social regard: evolving a psychology of cooperation. — In: The evolution of primate societies (Mitani, J.C., Call, J., Kappeler, P.M., Palombit, R.A. \& Silk, J.B., eds). The University of Chicago Press, Chicago, IL, p. 565-584.

Jensen, K., Hare, B., Call, J. \& Tomasello, M. (2006). What's in it for me? Self-regard precludes altruism and spite in chimpanzees. - Proc. Roy. Soc. Lond. B: Biol. Sci. 273: 1013-1021.

Lakshminarayanan, V.R. \& Santos, L.R. (2008). Capuchin monkeys are sensitive to others' welfare. - Curr. Biol. 18: R999-R1000.

Liebal, K., Vaish, A., Haun, D. \& Tomasello, M. (2014). Does sympathy motivate prosocial behaviour in great apes? - PLoS One 9: e84299.

Massen, J.J.M., van den Berg, L.M., Spruijt, B.M. \& Sterck, E.H.M. (2010). Generous leaders and selfish underdogs: pro-sociality in despotic macaques. — PLoS One 5: e9734.

Massen, J.J.M., Luyten, I.J.A.F., Spruijt, B.M. \& Sterck, E.H.M. (2011). Benefiting friends or dominants: prosocial choices mainly depend on rank position in long-tailed macaques (Macaca fascicularis). — Primates 52: 237-247.

Melis, A.P., Hare, B. \& Tomasello, M. (2009). Chimpanzees coordinate in a negotiation game. — Evol. Hum. Behav. 30: 381-392.

Melis, A.P., Warneken, F. \& Hare, B. (2010). Collaboration and helping in chimpanzees. In: The mind of the chimpanzee (Lonsdorf, E.V., Ross, S. \& Matsuzawa, T., eds). The University of Chicago Press, Chicago, IL, p. 265-281.

Melis, A.P., Warneken, F., Jensen, K., Schneider, A.C., Call, J. \& Tomasello, M. (2011). Chimpanzees help conspecifics obtain food and non-food items. - Proc. Roy. Soc. Lond. B: Biol. Sci. 278: 1405-1413.

Palagi, E. \& Norscia, I. (2013). Bonobos protect and console friends and kin. — PLoS One 8: e79290.

Pfalzer, S. \& Ehret, G. (1995). Social integration of a bonobo mother and her dependent daughter into an unfamiliar group. - Primates 36: 349-360.

Silk, J.B. \& House, B.R. (2011). Evolutionary foundations of human prosocial sentiments. — Proc. Natl. Acad. Sci. USA 108: 10910-10917. 
Silk, J.B. \& House, B.R. (2012). The phylogeny and ontogeny of prosocial behavior. — In: The Oxford handbook of comparative evolutionary psychology (Vonk, J. \& Shackelford, T.K., eds). Oxford University Press, Oxford, p. 381-398.

Silk, J.B., Brosnan, S.F., Vonk, J., Henrich, J., Povinelli, D.J., Richardson, A.S. \& Shapiro, S.J. (2005). Chimpanzees are indifferent to the welfare of unrelated group members. Nature 437: 1357-1359.

Skerry, A.E., Sheskin, M. \& Santos, L.R. (2011). Capuchin monkeys are not prosocial in an instrumental helping task. — Anim. Cogn. 14: 647-654.

Stevens, J.R. (2010). Donor payoffs and other-regarding preferences in cotton-top tamarins (Saguinus oedipus). - Anim. Cogn. 13: 663-670.

Suchak, M. \& de Waal, F.B.M. (2012). Monkeys benefit from reciprocity without the cognitive burden. — Proc. Natl. Acad. Sci. USA 109: 15191-15196.

Takimoto, A., Kuroshima, H. \& Fujita, K. (2010). Capuchin monkeys (Cebus apella) are sensitive to others' reward: an experimental analysis of food-choice for conspecifics. Anim. Cogn. 13: 249-261.

Tan, J. \& Hare, B. (2013). Bonobos share with strangers. — PLoS One 8: e51922.

Tan, J. \& Hare, B. (2014). Bonobos are xenophilic. - Am. J. Phys. Anthropol. 153: 251.

Vonk, J., Brosnan, S.F., Silk, J.B., Henrich, J., Richardson, A.S., Lambeth, S.P., Schapiro, S.J. \& Povinelli, D.J. (2008). Chimpanzees do not take advantage of very low cost opportunities to deliver food to unrelated group members. - Anim. Behav. 75: 1757-1770.

Warneken, F. \& Tomasello, M. (2009). Varieties of altruism in children and chimpanzees. Trends Cogn. Sci. 13: 397-402.

Warneken, F., Hare, B., Melis, A.P., Hanus, D. \& Tomasello, M. (2007). Spontaneous altruism by chimpanzees and young children. - PLoS Biol. 5: e184.

Wobber, V. \& Hare, B. (2009). Testing the social dog hypothesis: are dogs also more skilled than chimpanzees in non-communicative social tasks? - Behav. Proc. 81: 423-428.

Wobber, V. \& Hare, B. (2011). Psychological health of orphan bonobos and chimpanzees in African sanctuaries. - PLoS One 6: e17147.

Wobber, V., Wrangham, R.W. \& Hare, B. (2010a). Bonobos exhibit delayed development of social behavior and cognition relative to chimpanzees. - Curr. Biol. 20: 226-230.

Wobber, V., Hare, B., Maboto, J., Lipson, S., Wrangham, R.W. \& Ellison, P.T. (2010b). Differential changes in steroid hormones before competition in bonobos and chimpanzees. — Proc. Natl. Acad. Sci. USA 107: 12457-12462.

Wobber, V., Herrmann, E., Hare, B., Wrangham, R.W. \& Tomasello, M. (2014). Differences in the early cognitive development of children and great apes. - Dev. Psychobiol. 56: 547-573.

Yamamoto, S. \& Tanaka, M. (2010). The influence of kin relationship and reciprocal context on chimpanzees' other-regarding preferences. — Anim. Behav. 79: 595-602.

Yamamoto, S., Humle, T. \& Tanaka, M. (2012). Chimpanzees' flexible targeted helping based on an understanding of conspecifics' goals. — Proc. Natl. Acad. Sci. USA 109: 35883592. 